\title{
Measurement errors in geographical labour mobility using data linkage: the Spanish case
}

\begin{abstract}
:
This paper analyses reliability and accuracy of the relationships between migration and employment status, when they are estimated using a linked data set. The analysis will be carried out using a new source, the Labour and Geographical Mobility Statistics, which is provided by the Spanish Statistical Office. This statistic is constructed by exact matching procedure, linking the Labour Force Survey with the Official Population Register. The findings reveal that in order to study accurately geographic labour mobility, timing and geographical coherence between the two data sets must exist, if not, causality relations between the labour market and geographical mobility cannot be properly analysed. Although our analysis is referred to the microdata quality and internal coherence of that new Spanish statistic, this conclusion can be extended to any linked data set for studying geographic labour mobility, including the population censuses mainly based on administrative data.
\end{abstract}

Keywords: LFS, Population Register, geographic mobility, labour market, record linkage.

JEL Classification: J61, C81 and Y10

\section{Introduction}

According to Künn (2015), data linkage can supplement highly reliable administrative records with survey information that is crucial for statistical analysis but is usually unobserved in the administrative information. As a result, the linked data set contains a large number of variables providing an optimal data source for statistical analysis. It can also afford new insights into methodological questions regarding the validation of survey information with administrative records, vice versa or simultaneously ${ }^{1}$. Data linkage may also lead to shorter interviews, less respondent burden, and an overall reduction in survey costs. Furthermore, administrative data can potentially offer a significant increase in the number of auxiliary variables that may be used for nonresponse bias adjustment (Sakshaug et al. 2012, 2017).

\footnotetext{
${ }^{1}$ See, for example, Oberski et al. (2017) or Angel et al. (2019).
} 
The aim of this paper is to analyse the reliability and accuracy of the relationships

31 between migration and the employment status, when they are estimated using a linked data

set. The analysis will be carried out using the Labour and Geographical Mobility Statistics (LGMS), which is provided by the Spanish Statistical Office (Instituto Nacional de Estadistica, INE). The LGMS is constructed by linking the employment information of those people surveyed by the Spanish Labour Force Survey (LFS) with the residential mobility data drawn from the Spanish Population Register (PR). As a result, the relationships between geographical and labour mobility can be studied, taking advantage of the extraordinary amount of personal and employment information contained in the LFS.

Our mainly contribution to the literature is the following. In order to study properly the relationships between migration and labour market status using a linked data set, timing and geographical coherence between the two data sets must exist. If that coherence does not exist, then causality relations between the labour market and geographical mobility cannot be properly analysed. Although our analysis is referred to the microdata quality and internal coherence of a new statistic produced in Spain by merging survey and administrative data, this conclusion can be extended to any linked data set for studying geographic labour mobility, including the population census constructed exclusively through the register linkage method - as 15 National Statistical Offices have planned to do for the 2021 census round (UNECE, 2019).

The paper is structured as follows. After a brief review of methodological aspects about linked data set for studying geographic and labour mobility in Section 2, the internal coherence of the LGMS is addressed in section 3. This coherence is achieved by carrying out an exhaustive analysis of the concordance of the information that is simultaneously drawn from both sources regarding the place of residence in the previous year. As we will prove that 
the concordance of information on recent migration is very low, we will try to separate the theoretically coherent records in the sample from the rest, and determine whether there are any significant differences between the two groups of records. Provided that the coherent records faithfully represent the whole sample in which there is mobility, it is possible to use only this part of the information. However, if the characteristics of the coherent individuals differ from the rest, the estimated relationships between migrations and the labour market will be biased. This is what Section 4 seeks to determine. The paper ends with the main conclusions and recommendations.

\section{Methodological aspects about linked data set for studying geographic and labour mobility}

In Europe, since the beginning of the 2000s, both the Statistics Offices of the Nordic countries

(Denmark, Finland, Iceland, Norway and Sweden) and the Netherlands Centraal Buerau voor de Statistiek have been gaining extensive experience in the use of administrative records to produce official statistics (Kupiszewska et al., 2010). The experience has gradually extended promoted by institutions such as the UNECE $(2007,2011)$ and the EUROSTAT (2013)- and, currently record linkage is a normal procedure in the official production of statistical information.

In the USA, the Census Bureau operates with a congressional mandate to use

71 administrative records to improve, cut costs associated with, and reduce the respondent burden on Census Bureau surveys such as the American Community Survey, as well as the decennial census (Foster et al. 2018 a, b). In fact, in 2012 the linking procedures had already been suggested to reduce the lack of response in the 2010 Census (Rastogi and O'Hara 2012) or they had been used to generate longitudinal samples from the Current Population Survey

76 (Rivera-Drew et al. 2014). Additionally, throughout 2018, the interest in linking sources 
resulted in a large number of working papers by the Center for Administrative Records Research and Applications (CARRA) of the US Census Bureau.

Despite the increase in the production of linked data set, there is little experience of linking surveys and administrative registers in order to study relations between the labour market and geographical mobility. An example is Goetz (2017) for the US. He presents a novel data set combining survey information from the American Community Survey (ACS) with administrative data on employment from the Longitudinal Employer-Household Dynamics (LEHD) database, with the aim of studying geographic labour mobility. Using a personal identifier, an ACS individual is linked to all of their LEHD-covered jobs, and the crucial piece of information for the purpose of measuring job migration is in the geographic location of the employee's workplace establishment. Goetz states that the existing US surveys that include a longitudinal component, such as the Current Population Survey, do not follow an individual after they leave their residence, making it impossible to determine where the individual moved to.

The ACS-LEHD database provides detailed information about the respondent's situation only during the time before and during their move. The individual data from this survey (demographic, labour, income and household information) are available when the survey is carried out, whereas the data from the records - which are updated on a quarterly basis - are available for the following period. When the survey respondent appears in the post-compiled employment records with a job in a different place to the survey location, a migration has taken place. Thus, with the ACS-LEHD the forward migration sequence may be studied, provided that the respondent continues to have a job or has just found one, switching their status from being unemployed to being employed. However, the relationship between 
unemployment and mobility cannot be analysed using the ACS-LEHD, because in order to

101 appear in the administrative records, individuals have to be employed. In Europe, information from the LFS does not offer this drawback, because when the backward sequence is contemplated, the LFS provides the demographic, employment and

104 household information of individuals at the present moment and that of their labour aspects 105 in year before ${ }^{2}$. Thus, if the LFS is combined with a suitable population register, which allow 106 researchers to track previous residential mobility, all links between the labour market and geographical mobility can be established, irrespective of the employment status. Therefore,

108 the relationship between unemployment and geographical mobility could be perfectly studied. Not all European countries can make that combination, depending on the existence or 110 not of a suitable population register. Spain is one of the European countries whose population 111 register allows you to do that. Specifically, the Municipal Population Register is the 112 administrative register of inhabitants in a municipality (usual domicile) and its data constitute 113 proof of residence. The Town Councils are responsible for maintaining these registers and are 114 required to communicate monthly variations to the INE (Acts $4 / 1996$ and $7 / 1985$ ) so that this 115 institution can carry out checks to correct errors and duplicates. Based on this information, 116 since 1996 the INE has generated a centralized file, the Continuous Population Register (in 117 Spanish, Padrón Continuo). Registration of changes of residence is compulsory in Spain, but 118 there is no guarantee of complete coverage of flows since compliance depends on the 119 (dis)incentives for registration of movements. To register, the only documents required are 120 proof of identity (identity card, driving license, passport, etc.) and some kind of evidence of

\footnotetext{
${ }^{2}$ It must be noted that the LFS also contains some retrospective information about the previous place of residence but, in the majority of EU countries, the LFS sample design leads to a systematic underestimation of mobility, in the case of recently arrived immigrants (see Martí and Ródenas, 2007, 2012). We will not address this here because in the LGMS the administrative register determines the mobility, not the LFS information.
} 
121 residence at the address (title deeds, rental agreement, utility bills, or a letter from the first

122 adult already registered at the address). When a registration is accepted, de-registration at

123 the previous municipality is generated automatically. A local residency certificate is required

124 to access basic services such as public education or health care, to vote in elections, to renew

125 identity cards, to obtain grants, public employment, parking permits or home purchasing

126 grants. In the immigrant regularization programs, this certificate was considered as proof of

127 residence in Spain for illegal foreign immigrants. The PR is continuously updated and annually

128 disseminated. It covers all persons living in the national territory

129 Given the characteristics of the PR, the Spanish Statistical Office can merge the

130 residential mobility data drawn from the PR with the employment information of those people

131 surveyed by the Spanish LFS $^{3}$. This statistic, the LGMS, is produced by exact matching

132 procedure. Basically, there are two procedures to match record pairs. Both require the two

133 data sets to contain overlapping information. The most straightforward technique is based on

134 one or more unique personal identifiers, such as Social Security or identity card number ${ }^{4}$. In

135 this ideal case, the data can be directly linked, usually with almost no error. In the literature,

136 this procedure is known as "exact matching" (Künn, 2015). The other technique, probabilistic

137 linkage ${ }^{5}$, is used when there are no unique personal identifiers or when they are not reliable

\footnotetext{
3 The Spanish LFS has been conducted by the INE since 1964 and covers the entire national territory. This quarterly survey is aimed at population living in family dwellings, and intended to collect data on the labour force and its various categories (employed, unemployed) as well as on the population outside the labour market (inactive). The quarterly sample size is taken from about 65,000 dwellings, equivalent to approximately 160,000 people. The Spanish LFS is completely harmonized with the standards established by the EUROSTAT for the UELFS.

${ }^{4}$ Other examples of unique identifiers relating to people are tax identification numbers or health insurance numbers, for example.

${ }^{5}$ See, for example, Zhu et al. (2015), Herzog et al. (2007) or ASPE (2002). From a theoretical point of view, the specific problems that may appear when surveys are linked with administrative records using these techniques can be found in Blom and Korbmacher (2018), Sakshaug (2018a, 2018b) or Di Consiglio and Tuoto (2018).
} 
138 in the overlapping information. In that case, nonunique identifiers (like first and last name or 139 date of birth) are used to obtain likely record pairs. Particularly, in the Spanish LGMS, the personal identification card number (Documento

141 Nacional de Identidad -DNI- for nationals or Número de Identidad de Extranjero -NIE- for 142 foreign nationals) (INE, 2013, p. 12) is used in the matching procedure. According to Spanish 143 law, this may be done without requesting consent. In this way, the INE directly links the 144 personal data of all of the responders in the LFS over the age of 16 with the corresponding 145 records in the PR. Therefore, in this particular case, there is no reason to expect any bias due 146 to a lack of consent.

Non-consent errors may appear in those countries where respondents are explicitly

148 asked for permission to link their survey information to the corresponding administrative 149 records, and not all of them agree to the linkage. Sakshaug and Antoni (2017) and 150 Gessendorfer et al. (2018) discuss about the consequences of non-consent. Its implications 151 are twofold. First, the effective sample size is reduced and thus standard errors of estimates 152 are inflated. And, second, systematic error in the linked-data estimates can arise if 153 respondents who consent to the linkage are different from those who do not. In other words, 154 precision and bias problems arise ${ }^{6}$.

155 The exact or deterministic linkage procedure is the least prone to error, but some kind 156 of error can occur. Sakshaug and Antoni (2017, p. 561) point out that "a unique identifier 157 obtained from the survey respondent may be incomplete or recorded with error and thus may 158 not correspond to the same unit located in the administrative database". Moreover, these 159 identifiers may not be centralized and as Sakshaug and Antoni (2017, p. 565) said "a lack of

\footnotetext{
${ }^{6}$ See Abowd et.al (2018) or Sakshaug et.al (2012) for a discussion on the biases that the requisite of personal consent can generate, even with exact linkage.
} 
160 coordination may result in numbers being issued more than once". In addition, "survey

161 respondents may remember and report their originally issued identification numbers correctly,

162 but still provide invalid numbers, because they are unaware that their individual numbers

163 have been changed within the administrative records". This kind of problem is insignificant in

164 the LGMS for two reasons. First, the LFS sample is directly drawn from the PR, which contains

165 the unique identifier. Thus, the respondent does not provide the identifier. Second, the

166 Spanish identifiers (like in Nordic countries) are issued very early in a person's life -for

167 everyone older than 16 years-, are time-consistent and used by the whole Spanish

168 Administration. Thus, as expected, the linkage rate between the LFS and the PR is $99.4 \%$ (INE

169 2018); that is, $99.4 \%$ of the people over 16 years old surveyed by the LFS have also been found

170 in the PR.

171 From this methodological point of view, the linkage process in the LGMS is high quality

172 because it is used an exact matching procedure, non-consent errors are not expected and

173 identifiers problems are irrelevant. Therefore, this new source is a good example to prove the

174 accuracy of the relationships between mobility and labour status when it is used the linkage

175 procedure.

176 3. The internal consistency in the LGMS: place of residence in the previous year

177 The accuracy of the estimations of geographic labour mobility depends on the internal

178 consistency in the dataset in relation to date, origin and destination of the movements.

179 The LGMS is carried out on a yearly basis and incorporates some specific variables

180 derived from the PR into the sample of the LFS of the first quarter of each year. The individual

181 records of the LGMS should contain identical information in the comparable constructs drawn

182 from both statistical sources. This is the case of the place of residence in the previous year. 
will be equal to the total of those who have been registered in the PR of their municipality for less than 12 months.

Table 1 shows the total numbers of people by place of residence in the previous year

from both sources. It can be seen that every year the PR mobility more than doubles that of

193 the $\mathrm{LFS}^{7}$. Moreover, if the two migration variables are crossed, additional problems arise as

194 not all of the records coincide with their classification. Reading by columns and in relative 195 terms, in general only $20-24 \%$ of those who have been registered for less than one year in the 196 PR have declared in the LFS that they resided in a different place one year before. For example, 197 for 2016 only 199,700 people coincide, representing $23.6 \%$ of the 846,267 that showed 198 mobility according to the PR. In reality, the majority - between $76 \%$ and $80 \%$ - of the population 199 that have been registered for less than one year, stated in the LFS that the previous year they 200 were residing in the municipality where the survey was conducted. Reading by rows in Table 20111 , an average of around 50\% declared in the LFS that they resided in a different municipality 202 the year before while being registered in the PR for more than one year in the municipality. In 2032016 , for example, 212,369 people were in that situation $(51.5 \%$ of 412,069$)$.

\footnotetext{
${ }^{7}$ The focus of this paper is not to assess which data set measures mobility better. A discussion of this issue can be found in Martí and Ródenas (2004, 2007, 2012) or Ródenas and Martí (2009). Here our objective is to explain the reasons for the differences in the mobility estimations provided by the PR and the LFS based on an identical set of individuals.
} 
The only justification for these results is that the two initial assumptions are not confirmed. This means i) that there may be a significant lack of coherence between the place of registration and that of the survey and ii) that there may be significant delays in the inscription. To assess the first assumption, the only information provided by the INE (2018) is that the linkage rate between the LFS and the PR is $99.4 \%$ of those surveyed. This only means

that the inscriptions in the PR of almost all of the people interviewed for the LFS in the first

211 quarters of each year were found, but it is not the proportion of the LFS records that have 212 been effectively found and surveyed in the municipality in which they are registered ${ }^{8}$. The 213 observation of this assumption is fundamental. If the spatial coherence rate were not 214 sufficiently high, the quality and reliability of the LGMS would be brought into question. Let 215 us consider an example: an unemployed person, interviewed by the LFS in Madrid who does 216 in fact reside in this city but is and has been registered since birth in his or her city of origin, 217 for example Barcelona. Obviously, if it is not taken into account that the place of the interview 218 and the place of registration are different, when the labour data are linked with those of the 219 PR, it may be wrongly concluded that unemployed people have a low propensity to emigrate, 220 when the situation is precisely the opposite.

For the population aged sixteen years or over, Table 2 contains all of the situations that 222 may arise as a result of the crossing of the possible values of the LFS and PR mobility variables, 223 distinguishing the place of origin of the migratory movement. In this way, those who declare 224 in the LFS that they have changed residence with respect to the previous year are 225 disaggregated in accordance with whether they were previously residing in Spain or abroad.

\footnotetext{
${ }^{8}$ Although, on more than one occasion in private conversations, the INE has confirmed a very high percentage of coherences between the municipality of the LFS survey and that of residence according to the PR, they have not published this data or provided any figures.
} 
Also, for those who have been registered for less than one year in the municipality, the PR variable that establishes the relationship between the current municipality and the previous one has been used to distinguish those who have never moved from their place of birth, from those who have come from abroad and from those who have come from Spain.

In Table 2, the 18 coherence possibilities established are shown, which leads to three main types of records: those that are coherent, those that are not coherent but explainable, and finally, those that are incoherent. The coherence that can be guaranteed is limited to those records in which the LFS and the PR coincide both in terms of the time period that has 236 elapsed since the movement (more or less than one year) and the place of origin (Spain or 237 abroad). The assumption here is that when there is time and geographical coherence, there is 238 no reason to believe that there would not also be coherence between the place of the survey 239 and the place of registration. Under this assumption, the coherent records (white boxes) will be made up of the 4th,

2415 th, 6th, 8th and 15th groups. The first three are those without mobility in either of the two 242 sources and the second two are those with mobility declared in the LFS and confirmed 243 geographically and in terms of time by the inscription in the PR. Meanwhile, the records that 244 are not coherent but explainable (light grey boxes) will be divided into three sub-types. First 245 that of non-coherent records that are easily excusable due to the existence of two forms of 246 delay in the inscription in the PR (2nd and 3rd groups and 10th, 11th and 12th groups) and 247 those who did not de-register before emigrating abroad and who have now returned (16th, 248 17th and 18th groups). The individuals in the 2 nd and 3 rd groups declare that they reside in the same 250 municipality as one year before, but they have been registered for less than 12 months. If the 
251 place of registration and the LFS interview coincide (as stated by the INE), they would be

252 immigrants who had arrived more than one year before but who had not registered when

253 they arrived, but during the last 12 months; in other words, with a delay. If the place of the

254 interview does not coincide with the place of registration, there is no other alternative than

255 to consider that these are false registrations. In the 10th, 11th and 12th groups, the individuals

256 declare that they have recently moved, but according to the PR they have been registered in

257 their current municipalities since they were born or for more than one year. In this case, the

258 most rational option is to think that the place of the survey and that of registration are not

259 the same. These are recent immigrants who have still not registered in the PR because they

260 have not had the time or need to register in their new municipality. However, if the place of

261 the survey and registration coincides, this situation can only be explained by a high level of

262 circularity (coming and going) migrations with no change in the initial inscription in the PR.

263 The last three groups of records -16 th, 17th and 18th-, correspond to those who

264 declare that they had been residing abroad one year before, but who have been registered

265 for more than one year (or since their birth) in a municipality in Spain. This type of

266 inconsistency could be justified by short round trips, which is why these people have never

267 de-registered in Spain. In the case of foreigners, the mismatch could be explained by short

268 temporary stays in their places of origin. For the Spaniards, the explanation may be very

269 different. Their departure abroad and their fast return (without de-registration from the PR)

270 may correspond to the young Spaniards who left the country due to the economic crisis, were

271 not successful in their destination and have now returned.

272 Finally, the series of incoherent records (dark grey boxes) are made up of the 1st, 7th,

273 13th, 9th and 14th groups. In the first three groups, an absurd situation arises because nobody

274 over the age of 16 can be registered in the PR since birth if the inscription was made less than 
276 groups, incoherence arises because the individuals have declared that they have moved 277 recently and have also recently registered in the PR, but the places of origin (Spain or abroad) 278 do not coincide in the two sources.

We have estimated the volume of these eighteen groups for the period 2010-2016 using the LGMS microdata 9 . Table 2 shows their annual average distribution in terms of the total population. It should not be surprising that practically the whole population is concentrated in the groups without declared mobility in the LFS and registered in the PR for more than 12 months, given the traditionally low migration rate of the Spanish population.

284 These three groups, $97 \%$ of the population of the LGMS, are classified coherently by the LFS and the PR, assuming the condition the place of the survey coincides with the place of registration is met.

However, this absolute predominance of the apparently coherent records masks the degree of discrepancy between the LFS and the PR when there are migrations. If the percentage distribution is calculated only for those individuals who had mobility (the 4th, 5th and 6th groups are omitted), the percentage of the population with coherent mobility 291 information in both sources rises to $16.5 \%$ (the sum of the weights of the 8th and 15th groups, 292 in brackets in Table 2).

With respect to the records considered as being not coherent but explainable due to 294 the existence of a possible delay in registration, the 2 nd, 3rd, 10th, 11th and 12th groups 295 represent the majority of those classified. In particular, there is a strong concentration in the 296 2nd and 3rd groups (around 64.4\%), referring to those who have declared being in their 297 current residence for more than one year but who have been registered in the PR for less than

\footnotetext{
${ }^{9}$ The microdata files can be obtained on request at the INE.
} 
299 interview takes place coincides with that of registration. The records of the 10th, 11th and 300 12th groups can be reasonably explained when we accept that these individuals have just 301 moved but have not yet registered in the PR of the new municipality; thus, the place of the 302 interview does not coincide with that of their registration. In the case of the other type of reasonable lack of coherence, those who declare that 304 they had been residing abroad one year before but never de-registered from their 305 municipality of residence (the 16th, 17th and 18th groups) account for no more than $2.4 \%$. $0.9 \%$ in total. All of the incoherencies in the 14th (9th) group correspond to individuals who declare in the LFS that they were residing abroad (in Spain) one year before, but that in their recent inscription in the PR less than one year before they indicated that their previous residence was in Spain (abroad). Only under the ad-hoc afore-mentioned assumptions, can the migratory information 312 of the LFS and the PR be considered as being coherent for practically all (99.1\%) of the LGMS 313 sample in which there is mobility. Specifically, for $16.5 \%$ of the records (8th and 15th groups) 314 consistence exists per se, but for the remaining $-82.6 \%$ which are non coherent but 315 explainable-, it would be necessary to acknowledge that there is a delay in the registration in 316 the municipality of residence (2nd and 3rd groups, $64,4 \%$ ); that the current place of residence 317 does not always coincide with the place of registration (10th, 11th and 12th groups, 15.7\%) 318 and, finally, that movements abroad with non-registered returns in the PR have also taken 319 place (2.5\%, sum of the 16 th, 17 th and 18 th groups). Nevertheless, using the previous arguments to give internal coherence to the 321 migratory information of the LGMS seriously weakens the capacity of this source to capture 
the sign and intensity of the geographic labour mobility. The reason is simple: for the great

323 majority of the individuals interviewed, the timing of the migratory information does not

324 coincide with the timing of the labour information. This means that the accuracy of the 325 estimated links between mobility and the labour market situation cannot be ensured.

326 4. Differences between the sub-samples of the coherent and incoherent records with mobility

328 This problem of internal consistency would not be serious, if the coherent records faithfully represented the whole of the sample showing mobility. However, as the characteristics of the individuals making up the coherent $(16.5 \%)$ and the rest of the groups $(83.5 \%)$ differ, the estimated relationships between migrations and the labour market will be biased. In this section we will focus on assessing the similarity in the distribution of some selected individual

333 characteristics (age, relationship with the household reference person, gender, place of birth 334 and years of residence in Spain) and some labour market related ones (employment, time 335 working in the company, type of contract, job search time and recipients of unemployment 336 benefits).

Figure 1 summarizes the main categories of all these characteristics. We can see that age and relationship with the household reference person are the only variables that do not show substantial differences between the two main groups. However, the similarities end here.

In order to statistically determine whether the afore-mentioned characteristics are 343 homogeneously distributed between the group of coherent records and the rest, different 344 measurements and significance tests have been used Once it was confirmed that the two 345 quantitative variables (years of residence in Spain and the length of the relationship with the 
company) are not normally distributed between the two groups of records, a non-parametric

347 test for two independent samples, the Mann-Whitney-Wilcoxon " $U$ " test, was performed. The 348 same test has been used for the ordinal categorical variables, age and length of job search. In 349 the four cases, significant differences have been found in the distribution of the characteristic 350 depending on whether or not the records belong to the coherent group.

Finally, the non-parametric test used for the rest of the seven nominal categorical

352 variables was the Pearson's $\chi^{2}$. For all of them, the null hypothesis that the characteristic is

353 distributed homogeneously between the two groups of records was rejected. Since, by 354 definition, the $\chi^{2}$ statistic tends to establish that there are differences when the samples are 355 very large, some additional measurements based on the value of the $\chi^{2}$ have been used. These 356 either reduce the effect of the sample size in the estimated relationship (contingency 357 coefficient, Phi $(\phi)$ and Cramer's V), or are based on the proportional reduction of the error 358 (Lambda, Goodman and Kruskal's Tau or Theil's uncertainty coefficient). When using these 359 measurements it can be observed that the differences between the coherent records and the 360 rest are statistically significant.

361 Taking the differences and its statistically significance into account ${ }^{10}$, it is obvious, 362 therefore, that the strictly coherent group does not represent the whole of the LGMS sample.

363 This means that if only the sub-sample of coherent records is used, significant biases will arise 364 when the relationship between mobility and employment variables is estimated.

\section{5. Conclusions}

366 The aim of this paper is to analyse the reliability and accuracy of the relationships between 367 mobility and labour market, when they are estimated using a linked data set. Although, there

\footnotetext{
${ }^{10}$ A level of significance $(\alpha)$ of 0.05 has been used and the records of the sample have been weighted for all observational units in LGMS. The p-value associated to each estimator is equal to 0 in all the proofs.
} 
368 is little experience of linking surveys and administrative registers in order to study geographic

369 labour mobility, the new source, LGMS, is a good example to prove that because of the high 370 quality of the linkage process. Particularly, LGMS is constructed by exact matching procedure, 371 non-consent errors are not expected and identifiers problems are irrelevant. The accuracy of the estimations of geographical labour mobility depends on the 373 internal consistency in the dataset. In that sense, an exhaustive analysis has been made of the 374 information regarding the recent migration. In order to confirm the coherence in the place of residence one year before, it has been necessary to assume that for $64.4 \%$ of the sample there is a delay in the registration in the municipality in which the individual effectively resides, that for another $15.7 \%$ the current place of residence does not coincide with the place of registration and, finally, it must be accepted that for $2.5 \%$ of the records, movements have been made abroad with returns that have not been registered in the PR. Therefore, for the majority of the LGMS records, the timing 381 of the migratory information not coincides with the timing of the employment information. 382 Consequently, a satisfactory level of accuracy of the estimated associations between mobility 383 and employment status cannot be guaranteed. However, the problem of internal consistency timing would not be serious if the 385 coherent records faithfully represented the whole sample with mobility in the LGMS. Of the 386 ten characteristics studied, only the variables of age and the relationship with the household 387 reference person do not graphically reveal substantial significant differences in the distribution 388 of their main categories between the group of coherent records and the rest. But the 389 similarities end here. None of the other variables are similar enough. Moreover, the statistical 390 tests used determine that these variables are not distributed homogeneously between the 391 coherent group of records and the others. Given these results, the use of the LGMS, at least 
residence is the place of LFS survey) is not advisable.

In general, the findings reveal that in order to study accurately geographic labour

mobility using linking data set, timing and geographical coherence between the two data sets

must exist, if not, causality relations between labour and geographical mobility cannot be

properly analysed.

Finally, we can also extend this conclusion to the population censuses that are mainly

not, the correlation between mobility and employment -or any other individual features- will

not be accurate. Moreover, the demographic and socioeconomic features of population,

which theoretically belong to a certain area, will be completely incorrect.

References

405

406

Abowd, J. M., Schmutte, I. M. \& Vilhuber, L. (2018). Disclosure limitation and confidentiality protection in linked data (Working Paper No. 18-07). Retrieved from Center for Economic Studies, U.S. Census Bureau website: https://ideas.repec.org/p/cen/wpaper/18-07.html.

Angel, S., Disslbacher, F. \& Humer, S. (2019) What did you really earn last year?: Explaining measurement error in survey income data. Journal of the Royal Statistical Society, A, 182 (part. 4), 1411-1437.

ASPE (2002). Studies of welfare populations: data collection and research issues. Two methods of linking: probabilistic and deterministic record-linkage methods. Retrieved from U.S. Department of Health \& Human Services website: https://aspe.hhs.gov/report.

Blom, A. G. \& Korbmacher, J. (2018). Linking survey data to administrative records in a comparative survey context. In D. L. Vannette \& J. A. Krosnick (Eds.), The Palgrave handbook of survey research, (pp. 267273). Doi: 10.1007/978-3-319-54395-6_34.

Di Consiglio, L. \& Tuoto, T. (2018). Population size estimation and linkage errors: the multiple lists case. Journal of Official Statistics, 34(4), 889-908.

EUROSTAT (2013). Microdata linking - international sourcing. Retrieved from Eurostat webpage: https://ec.europa.eu/eurostat/statistics-explained/index.php?title=Archive:Microdata linking international sourcing.

Foster, T.B., Ellis, M. \& Fiorio,L. (2018a). The Opportunities and Challenges of Linked IRS Administrative and Census Survey Records in the Study of Migration. CARRA Working Paper Series no2018-06. Retrieved from US Census Bureau website: https://www.census.gov/library/workingpapers/2018/adrm/carra-wp-2018-06.html.

Foster, T.B., Ellis, M. \& Fiorio,L. (2018b). Foreign-Born and Native-Born Migration in the U.S.: Evidence from IRS Administrative and Census Survey Records. CARRA Working Paper Series no2018-07. Retrieved from US Census Bureau website: https://www.census.gov/library/working-papers/2018/adrm/carra-wp2018-07.html.

Gessendorfer, J., Beste, J., Drechsler, J. \& Sakshaug, J.W. (2018). Statistical matching as a supplement to record linkage: A valuable method to tackle nonconsent Bias?. Journal of Official Statistics, 34(4), 909-933. 
Goetz, C. F. (2017). The Potential for Using Combined Survey and Administrative Data Sources to Study Internal Labor Migration (Working Paper No 17-55). Retrieved from Center for Economic Studies, U.S. Census Bureau website: https://ideas.repec.org/p/cen/wpaper/17-55.html.

Herzog, T. N., Scheuren, F. J. \& Winkler, W. E. (2007). Data quality and record linkage techniques. New York, NY: Springer.

INE (2013). Estadística de Movilidad Laboral y Geográfica. Explotación estadística de la Encuesta de Población Activa y de la Base Padronal del INE. Metodología y descripción general de la operación. Retrieved from INE website: https://www.ine.es/metodologia/t22/t2230209.pdf.

INE (2018). Labour market and migration statistics. Standardised Methodological Report. Retrieved from INE website: https://www.ine.es/dynt3/metadatos/en/RespuestaDatos.html?oe=30209.

Kupiszewska, D., Kupiszewski, M., Martí, M. \& Ródenas, C. (2010.) Possibilities and limitations of comparative quantitative research on international migration flows (Working Paper No4). Retrieved from European Commission webpage: https://ec.europa.eu/migrant-integration/librarydoc/prominstatworking-paper-no-04---possibilities-and-limitations-of-comparative-quantitative-research-oninternational-migration-flows.

Künn, S. (2015). The challenges of linking survey and administrative data. Retrieved from IZA World of Labor website: $\quad$ https://wol.iza.org/uploads/articles/214/pdfs/challenges-of-linking-survey-andadministrative-data.pdf?v=1.

Martí, M. \& Ródenas, C. (2004). Migrantes y migraciones: de nuevo la divergencia en las fuentes estadísticas [Migrants and migrations: again the divergence in the statistical sources]. Estadística Española, 46(156), 293-321.

Martí, M. \& Ródenas, C. (2007). Migration estimation based on the Labour Force Survey: An EU-15 perspective. International Migration Review, 41(1), 101-126.

Martí, M. \& Ródenas, C. (2012). Measuring international migration through sample surveys: some lessons from the Spanish case. Population-E, 67(3), 435-464.

Oberski, D.L., Kirchner, A., Eckman, S. \& Kreuter, F. (2017). Evaluating the quality of survey and administrative data with generalized multitrait-multimethod models. Journal of the American Statistical Association, 112(520), 1477-1489.

Rastogi, S. \& O'Hara, A. (2012). 2010 Census Match Study. Final Report. US Census Bureau. Retrieved from US Census Bureau website: https://www.census.gov > 2012 > dec > 2010_cpex_247.

Rivera-Drew, J.A., Flood, S. \& Warren, J.R. (2014). Making full use of the longitudinal design of the Current Population Survey: Methods for linking records across 16 months, Journal of Economic and Social Measurement, 39, 121-144.

Ródenas, C. \& Martí, M. (2009). Estimating false migrations in Spain. Population-E, 64(2), 361-376.

Sakshaug, J.W. (2018a). Methods of linking survey data to official records. In D. L. Vannette \& J. A. Krosnick (Eds.), The Palgrave handbook of survey research, (pp. 257-261). Doi: 10.1007/978-3-319-54395-6_34.

Sakshaug, J.W. (2018b). Linking survey data to official government records. In D. L. Vannette \& J. A. Krosnick (Eds.), The Palgrave handbook of survey research, (pp. 597-606). Doi: 10.1007/978-3-319-543956_34.

Sakshaug, J. W. \& Antoni, M. (2017). Errors in linking survey and administrative data. In Biemer, P. P., de Leeuw, E., Eckman, S., Edwards, B., Kreuter, F., Lyberg, L. E., ... West, B. T. (Eds.), Total survey error in practice (pp. 557-573). Hoboken, NJ: John Wiley \& sons.

Sakshaug, J.W., Antoni, M. \& Sauckel, R. (2017). The quality and selectivity of linking federal administrative records to respondents and nonrespondents in a general population sample survey of Germany. Survey Research Methods, 11(1), 63-80.

Sakshaug, J.W, Couper, M.P., Ofstedal, M.B. \& Weir, D.R. (2012). Linking survey and administrative records: mechanisms of consent. Sociological Methods \& Research, 41(4), 535-569.

UNECE (2007). Register-based statistics in the Nordic countries. Review of best practices with focus on population and social statistics. Retrieve from UNECE website: http://www.unece.org/fileadmin/DAM/stats/publications/Register_based_statistics_in_Nordic_co untries.pdf.

UNECE (2011). Using Administrative and Secondary Sources for Official Statistics. A Handbook of Principles and $\begin{array}{llll}\text { Practices. } & \text { Retrieved UNECE }\end{array}$ https://www.unece.org/fileadmin/DAM/stats/publications/Using_Administrative_Sources_Final_f or_web.pdf.

UNECE (2019). 2020 Population Census round. Retrieved from UNECE website: https://statswiki.unece.org/display/censuses/2020+Population+Census+Round. 

linkage? A simulation study. Journal of Biomedical Informatics, 56, 80-86. 
Table 1: Population by place of residence in the previous year. 2010-2016

\begin{tabular}{|c|c|c|c|c|}
\hline \multirow{2}{*}{\multicolumn{2}{|c|}{$\begin{array}{l}\text { Place of residence one } \\
\text { year before (LFS): }\end{array}$}} & \multicolumn{3}{|c|}{ Years registered in the municipality (PR): } \\
\hline & & \multirow{2}{*}{$\begin{array}{r}\begin{array}{c}\text { Same } \\
\text { (more than one year) }\end{array} \\
37,322,223\end{array}$} & \multirow{2}{*}{$\begin{array}{l}\begin{array}{c}\text { Other } \\
\text { (less than one year) }\end{array} \\
922,606\end{array}$} & \multirow{2}{*}{$\begin{array}{l}\text { Total } \\
38,244,829\end{array}$} \\
\hline 2010 & Same & & & \\
\hline & Other & 254,422 & 225,721 & 480,143 \\
\hline & Total & $37,576,645$ & $1,148,327$ & $38,724,972$ \\
\hline \multirow[t]{3}{*}{2011} & Same & $37,544,593$ & 826,341 & $38,370,934$ \\
\hline & Other & 208,889 & 228,920 & 437,809 \\
\hline & Total & $37,753,482$ & $1,055,261$ & $38,808,743$ \\
\hline \multirow[t]{3}{*}{2012} & Same & $37,680,864$ & 774,231 & $38,455,095$ \\
\hline & Other & 211,037 & 188,037 & 399,074 \\
\hline & Total & $37,891,901$ & 962,268 & $38,854,169$ \\
\hline \multirow[t]{3}{*}{2013} & Same & $37,684,542$ & 689,995 & $38,374,537$ \\
\hline & Other & 184,114 & 174,584 & 358,698 \\
\hline & Total & $37,868,656$ & 864,579 & $38,733,235$ \\
\hline \multirow[t]{3}{*}{2014} & Same & $37,446,287$ & 668,185 & $38,114,472$ \\
\hline & Other & 183,277 & 185,852 & 369,129 \\
\hline & Total & $37,629,564$ & 854,037 & $38,483,601$ \\
\hline \multirow[t]{3}{*}{2015} & Same & $37,415,745$ & 676,734 & $38,092,479$ \\
\hline & Other & 217,786 & 206,923 & 424,709 \\
\hline & Total & $37,633,530$ & 883,657 & $38,517,187$ \\
\hline \multirow[t]{3}{*}{2016} & Same & $37,433,221$ & 646,567 & $38,079,788$ \\
\hline & Other & 212,369 & 199,700 & 412,069 \\
\hline & Total & $37,645,590$ & 846,267 & $38,491,857$ \\
\hline
\end{tabular}


Table 2: Population by residence in the previous year. Annual average 2010-2016.

\begin{tabular}{|c|c|c|c|c|c|c|c|c|c|}
\hline & & & \multicolumn{6}{|c|}{ Years registered in the municipality (PR): } & \multirow{4}{*}{ TOTAL } \\
\hline & & & \multicolumn{3}{|c|}{ Less than 1 year } & \multicolumn{3}{|c|}{ More than 1 year } & \\
\hline & & & \multicolumn{3}{|c|}{ Previous place of residence } & \multicolumn{3}{|c|}{ Previous place of residence } & \\
\hline & & & $\begin{array}{c}\text { No } \\
\text { variation } \\
\text { since birth }\end{array}$ & $\begin{array}{l}\text { Previous } \\
\text { residence in } \\
\text { Spain }\end{array}$ & $\begin{array}{l}\text { Previous } \\
\text { residence } \\
\text { abroad }\end{array}$ & $\begin{array}{l}\text { No variation } \\
\text { since birth }\end{array}$ & $\begin{array}{l}\text { Previous } \\
\text { residence in } \\
\text { Spain }\end{array}$ & $\begin{array}{l}\text { Previous } \\
\text { residence } \\
\text { abroad }\end{array}$ & \\
\hline \multirow{3}{*}{ 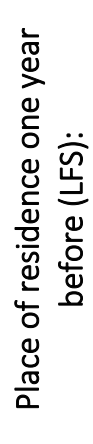 } & \multicolumn{2}{|c|}{ 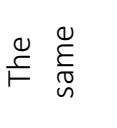 } & $\begin{array}{r}\text { Group 1: } \\
0\end{array}$ & $\begin{array}{r}\text { Group 2: } \\
630,328 \\
(54.6 \%)\end{array}$ & $\begin{array}{r}\text { Group 3: } \\
113,195 \\
(9.8 \%)\end{array}$ & $\begin{array}{r}\text { Group 4: } \\
14,133,325\end{array}$ & $\begin{array}{r}\text { Group 5: } \\
20,121,434\end{array}$ & $\begin{array}{r}\text { Group 6: } \\
3,249,166\end{array}$ & $38,247,448$ \\
\hline & $\begin{array}{l}0 \\
\frac{0}{0} \\
\frac{0}{2}\end{array}$ & $\begin{array}{l}\cdot \frac{5}{\sqrt{n}} \\
\stackrel{2}{n}\end{array}$ & $\begin{array}{r}\text { Group 7: } \\
0\end{array}$ & $\begin{array}{r}\text { Group 8: } \\
143,113 \\
(12.4 \%)\end{array}$ & $\begin{array}{r}\text { Group 9: } \\
3,330 \\
(0.3 \%)\end{array}$ & $\begin{array}{r}\text { Group 10: } \\
47,714 \\
(4.1 \%)\end{array}$ & $\begin{array}{r}\text { Group 11: } \\
116,139 \\
(10.1 \%)\end{array}$ & $\begin{array}{r}\text { Group 12: } \\
17,063 \\
(1.5 \%)\end{array}$ & 327,359 \\
\hline & 离 & $\begin{array}{l}0 \\
0 \\
0 \\
0 \\
\frac{1}{4}\end{array}$ & $\begin{array}{r}\text { Group 13: } \\
0\end{array}$ & $\begin{array}{r}\text { Group 14: } \\
7,361 \\
(0.6 \%)\end{array}$ & $\begin{array}{r}\text { Group 15: } \\
47,587 \\
(4.1 \%)\end{array}$ & $\begin{array}{r}\text { Group 16: } \\
8,060 \\
(0.7 \%)\end{array}$ & $\begin{array}{r}\text { Group 17: } \\
9,784 \\
(0.8 \%)\end{array}$ & $\begin{array}{r}\text { Group 18: } \\
11,510 \\
(1.0 \%)\end{array}$ & 84,303 \\
\hline \multicolumn{3}{|c|}{ TOTAL } & 0 & 780,802 & 164,112 & $14,189,099$ & $20,247,357$ & $3,277,739$ & $38,659,109$ \\
\hline
\end{tabular}

499

500 Figure 1: Distribution of main categories of selected characteristics between the coherent 501 migration group and the rest. Average 2010-2016

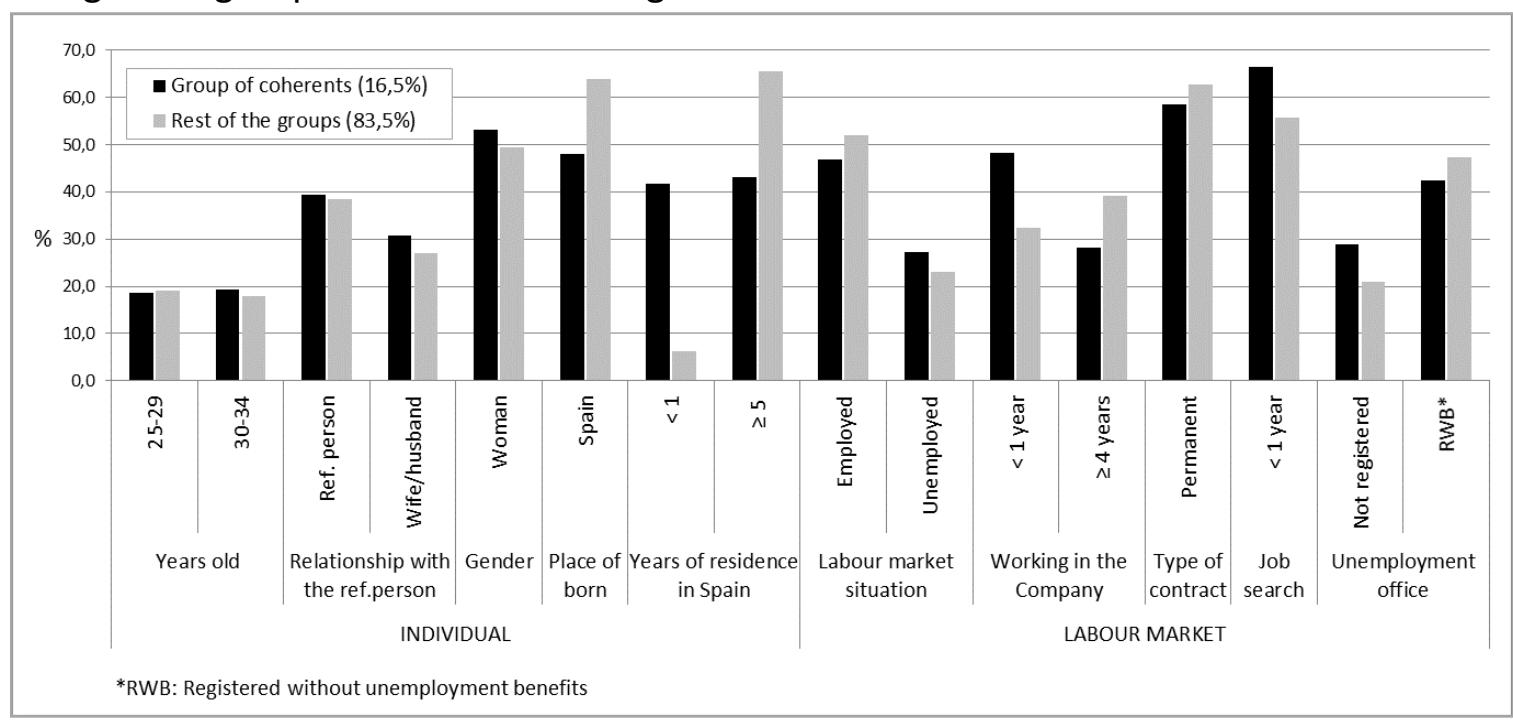

Source: LGMS and own elaboration. 